\title{
TRANS4: a new coupled electron/proton transport code - comparison to observations above Svalbard using ESR, DMSP and optical measurements
}

\author{
C. Simon ${ }^{1}$, J. Lilensten ${ }^{1}$, J. Moen ${ }^{2,3}$, J. M. Holmes ${ }^{3}$, Y. Ogawa ${ }^{4}$, K. Oksavik ${ }^{5}$, and W. F. Denig ${ }^{6, *}$ \\ ${ }^{1}$ Laboratoire de Planétologie de Grenoble, Grenoble, France \\ ${ }^{2}$ Plasma and Space Physics Group, Department of Physics, University of Oslo, Norway \\ ${ }^{3}$ Department of Arctic Geophysics, University Centre in Svalbard (UNIS), Longyearbyen, Norway \\ ${ }^{4}$ Solar-Terrestrial Environment Laboratory, Nagoya University, Japan \\ ${ }^{5}$ The Johns Hopkins University Applied Physics Laboratory, Laurel, MD, USA \\ ${ }^{6}$ Space Vehicles Directorate, Air Force Research Laboratory, Hanscom AFB, MA, USA \\ *now at: National Geophysical Data Center, NOAA, Boulder, CO, USA
}

Received: 2 August 2006 - Revised: 10 January 2007 - Accepted: 15 February 2007 - Published: 29 March 2007

\begin{abstract}
We present for the first time a numerical kinetic/fluid code for the ionosphere coupling proton and electron effects. It solves the fluid transport equations up to the eighth moment, and the kinetic equations for suprathermal particles. Its new feature is that for the latter, both electrons and protons are taken into account, while the preceding codes (TRANSCAR) only considered electrons. Thus it is now possible to compute in a single run the electron and ion densities due to proton precipitation. This code is successfully applied to a multi-instrumental data set recorded on 22 January 2004. We make use of measurements from the following set of instruments: the Defence Meteorological Satellite Program (DMSP) F-13 measures the precipitating particle fluxes, the EISCAT Svalbard Radar (ESR) measures the ionospheric parameters, the thermospheric oxygen lines are measured by an all-sky camera and the $\mathrm{H}_{\alpha}$ line is given by an Ebert-Fastie spectrometer located at Ny-Ålesund. We show that the code computes the $\mathrm{H}_{\alpha}$ spectral line profile with an excellent agreement with observations, providing some complementary information on the physical state of the atmosphere. We also show the relative effects of protons and electrons as to the electron densities. Computed electron densities are finally compared to the direct ESR measurements.
\end{abstract}

Keywords. Ionosphere (Auroral ionosphere; Particle precipitation) - Space plasma physics (Transport processes)

Correspondence to: J. Lilensten

(jean.lilensten@obs.ujf-grenoble.fr)

\section{Rationale: on the importance of proton precipitation}

1.1 Ground-based and rocket observations of hydrogen lines

Nearly 70 years ago, Vegard (1939) identified the signature of the two first hydrogen Balmer emission lines $\mathrm{H}_{\alpha}$ $(656.3 \mathrm{~nm})$ and $\mathrm{H}_{\beta}(486.1 \mathrm{~nm})$ in the auroral spectrum. Vegard and Tønsberg (1944) detected a Doppler broadening and a shift in the diffuse Balmer $\mathrm{H}_{\beta}$ lines. Vegard (1948) then proposed the first interpretation and ascribed this shift to a Doppler effect due to neutralized protons precipitating down in the ionosphere, soon confirmed by Gartlein (1950). High energy protons, originating from the magnetosphere and the solar wind, precipitate along the geomagnetic field lines into the ionosphere where they undergo charge-exchange collisions. Fast hydrogen atoms can be produced which in turn react with the ambient neutrals. Gartlein $(1950,1951)$ and Meinel (1951) used high-resolution spectroscopy techniques to identify this shift in $\mathrm{H}_{\alpha}, \mathrm{H}_{\beta}$ and $\mathrm{H}_{\gamma}$. Definitive theoretical support was given experimentally to this interpretation by Chamberlain (1954a, b) and Omholt (1956). Eather and Jacka (1966) made measurements in the magnetic horizontal and magnetic zenith direction; $\mathrm{H}_{\beta}$ appeared to be unshifted in the horizontal directions, while it experienced a 5 to $7-\AA$ blue shift in the zenith direction, together with a significant red shift of the tail of the distribution. The early steps that led to the understanding of the physics underlying the presence of hydrogen emission lines in the ionosphere are detailed by Eather (1967a). The zenith Doppler-shifted profiles indicate that field-aligned precipitating protons can travel at velocities up to $400 \mathrm{~km} \mathrm{~s}^{-1}$ in the upper atmosphere.

Published by Copernicus GmbH on behalf of the European Geosciences Union. 
The blue shift is due to the incoming protons precipitating along the geomagnetic field lines. The physical origin of the red-shifted wing of the distribution has been thoroughly discussed by e.g. Galand et al. (1998). They explain the red shift emission as being produced by neutralized $\mathrm{H}^{+}$ions travelling upwards after they underwent both collisional and magnetic angular redistributions.

$\mathrm{H}_{\alpha}$ and $\mathrm{H}_{\beta}$ lines observed by spectrophotometers have been reported for instance by Deehr et al. (1998), Sigernes et al. (1994) and Sigernes (1996). Little variation of the auroral brightness with latitude has been observed, except in the daytime polar cleft where profiles usually exhibit narrower shapes (Lorentzen et al., 1998). Other instruments such as the High Throughput Imaging Echelle Spectrograph (HiTIES) have recently been installed at Svalbard (Chakrabarti et al., 2001; Lanchester et al., 2003). HiTIES is aimed at examining the $\mathrm{H}_{\beta}$ line in the magnetic zenith with a spectral resolution of $1.3 \AA$, allowing long-duration exposures and a very good signal-to-noise ratio. In addition to these ground-based efforts, sounding rocket campaigns have been launched to study the proton aurora through its Balmer emission lines (Søraas et al., 1974, 1994, 1996). Coordinated experiments using rockets, ground-based spectrophotometers, incoherent scatter radars and orbiting satellites are the next step in the systematic study of proton events. In northern Norway, the Andøya Rocket Range near the Troms $\varnothing$ EISCAT UHF radar and the SvalRak launch site in Ny-Ålesund at Svalbard are well designed for such experiments.

\subsection{The proton transport modelling}

After the first theoretical background for emission lines established by Chamberlain (1957) and Omholt (1956), Eather and Burrows (1966) computed the hydrogen line profiles in a dipole field. They introduced the magnetic mirroring effect and showed that in this case a red shift component would be expected, soon to be clearly identified in the spectra.

The quantitative treatment of $\left(\mathrm{H}^{+}, \mathrm{H}\right)$ precipitations began at the same time with Monte Carlo simulations (Davidson, 1965) which were able to characterize the transverse spreading of an initial proton beam due to the charge-exchange processes. Following Eather (1967a, b) and Edgar et al. (1973, 1975), Henriksen (1979) assumed a plane parallel geometry together with forward scattering. Henriksen (1979) used the continuous slowing-down approximation (CSDA) by introducing a continuous loss function $L(E)$ to account for the energy loss of a wide stream of precipitating protons. This approximation is justified by the low energetic losses encountered in collisions with a neutral in comparison to the initial energy of the precipitating particles. Following the theoretical developments of Davidson (1965), Johnstone (1972) and Iglesias and Vondrak (1974), Jasperse and Basu (1982) described the spreading of a proton beam in a singleconstituent $\mathrm{N}_{2}$ atmosphere due to the charge-exchange collisions $\mathrm{H}^{+} \leftrightarrow \mathrm{H}$ (stripping and capture). They solved nu- merically Boltzmann's classical linear transport equation and computed a correction factor of $\varepsilon \approx 0.75$ due to the spreading effect accounting for the damping along the line of sight of the particle flux computed by the model. This damping factor is valid for an arc $200-\mathrm{km}$ wide in latitude under roughly $300 \mathrm{~km}$ altitude where the excitation/ionisation reactions begin to play a significant role in the spreading of the initial beam. Basu et al. $(1987,1990,1993)$ and Strickland et al. (1993) designed a proto-electron-hydrogen model based on kinetic transport equations. However, still no angular redistributions due to either magnetic or collisional mechanisms could be taken into account, which made the comparison between spectroscopic measurements and the model impossible to perform. Kozelov and Ivanov $(1992,1994)$ and Lorentzen et al. (1998) used a Monte Carlo scheme to study monoenergetic proton beams, which allowed dealing with the Doppler profiles and beam spreading effects. Contrary to the continuous slowing down approximations, Monte Carlo methods assume discrete stochastic energy transfers ruled by probability laws. Galand et al. $(1997,1998)$ solved for the first time the dissipative proton-hydrogen kinetic Boltzmann equation. The resolution consisted of an analytical solution of the coupled $\left(\mathrm{H}^{+}, \mathrm{H}\right)$ system by including dissipative forces in the divergence term of the Boltzmann equations. Galand (1996) showed that the energy losses associated with chargeexchange reactions and elastic collisions could be assumed to be continuous, which validated the entire approach. A wealth of different experimental and theoretical studies have been carried out lately (Jasperse, 1997; Lorentzen, 2000; Lummerzheim and Galand, 2001; Solomon, 2001; Chakrabarti et al., 2001; Basu et al., 2001; Fang et al., 2004; Hubert et al., 2004; Galand and Chakrabarti, 2006).

None of the previous studies have solved simultaneously the electron and proton kinetic transports and the fluid equations. We propose a new theoretical approach to account for this in a single numerical fluid/kinetic code called TRANS4. Within a single run of TRANS4, it is now possible to get the ion productions due to electron and proton precipitation from the kinetic part, whereas electron and ion densities or temperatures due to both protons and electrons are computed by the fluid part.

\subsection{TRANS4: coupling protons and electrons}

The numerical model TRANS4 is based on two approaches. The first set of codes is TRANSCAR (Lilensten and Blelly, 2002). TRANSCAR is a coupled kinetic/fluid model which solves sequentially the Boltzmann kinetic equation for suprathermal electrons and the Boltzmann momentum equations for $\mathrm{N}_{2}^{+}, \mathrm{O}_{2}^{+}, \mathrm{O}^{+}, \mathrm{N}^{+}, \mathrm{NO}^{+}$and $\mathrm{H}^{+}$ions between 90 and $3000 \mathrm{~km}$. Each part is linked with the other. The fluid part uses the ionisation and heating rates computed by the kinetic transport code; the kinetic part uses the electron density and temperature computed by the fluid part (Fig. 1). For the ion production, two mechanisms are taken into account. 


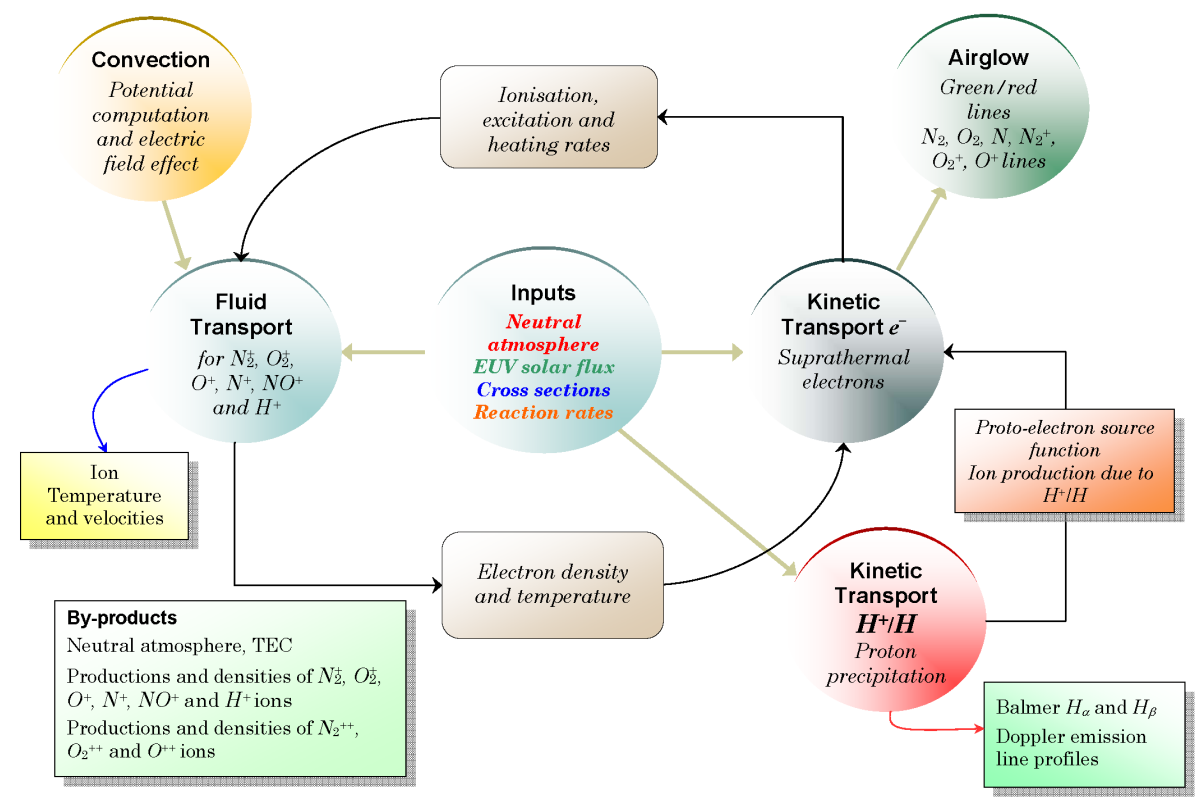

Fig. 1. Architecture of TRANS4, a multicoupled proto-electron kinetic/fluid transport numerical model.

First, the primary production is the ionisation of the thermosphere due to solar EUV (photoproduction) or to electron precipitation. Collisions of primary suprathermal electrons can in turn ionize the neutral gas. Ions and secondary electrons are generated. In order to take into account this additional ion production, we use a kinetic transport formalism which describes the 1-D vertical energy degradation of the suprathermal electrons in the ionosphere. This formalism constitutes the kinetic part of TRANSCAR (Lummerzheim and Lilensten, 1994).

The second set of equations describes the kinetic transport of $\left(\mathrm{H}^{+}, \mathrm{H}\right)$ particles. It is described in Galand et al. (1997, 1998) who solved for the first time the dissipative protonhydrogen kinetic Boltzmann equation. The resolution consists of an analytical solution of the coupled $\left(\mathrm{H}^{+}, \mathrm{H}\right)$ system, with the introduction of dissipative forces. It introduces a continuous loss function as an additional external force so that the set of coupled equations takes the form of a sparse matrix to invert. This code has been successfully tested using experiments (Lilensten and Galand, 1998). The computation of the hydrogen Balmer profiles uses the cross sections given by Basu et al. (1987) (excitation and ionisation cross sections), Kozelov and Ivanov (1992) (elastic cross sections), van Zyl and Neumann (1980) and Yousif et al. (1986) (emission $\mathrm{H}_{\alpha}$ and $\mathrm{H}_{\beta}$ cross sections through collisions of $\left(\mathrm{H}, \mathrm{H}^{+}\right)$ with $\mathrm{N}_{2}, \mathrm{O}_{2}$ and $\mathrm{O}$ ). The angular redistribution encountered by hydrogen particles is described by a phase function. In the following, we will study the effect of several theoretical formulations of this function (Rutherford or Maxwellian distribution). The Rutherford phase function for protons, equal to the Rutherford formula used for electrons (Stamnes, 1980), is centered on the pitch angle of the incoming particle and is controlled by a screening parameter equal to $1 \times 10^{-3}$ in the case of protons (Galand et al., 1998).

The two parts (kinetic proton on one hand, kinetic electron and fluid on the other hand) have always been run independently, introducing two kinds of inaccuracies. The first and minor one is simply due to the transfer of parameters through independent files. The second one is trickier. As any timedependent code, this one needs to reach an equilibrium before the results may be reliable. When the codes are run independently, the equilibrium is reached by running the kinetic transport of the electrons only (TRANSCAR code). The proton precipitation effects are then added to the system. When all the transports are considered simultaneously (TRANS4 code), the effects of the protons on the electron density are taken into account even during the starting phase. The discrepancy between the independent method and the integrated one can reach 5 percent on the final electron density.

\section{Application to a geophysical event using the ESR, DMSP and optics: 22 January 2004}

\subsection{General description}

We chose as a case study the 22 January 2004 . An extensive overview of this geophysical event is given by Lorentzen et al. (2007). The period of interest spans within half an hour about 08:45 UT at Svalbard, Norway $\left(78^{\circ} \mathrm{N}, 16^{\circ} \mathrm{E}\right)$. Multiple instruments were observing the ionosphere simultaneously. This study was set up for the Svalbard EISCAT Rocket Study of Ion Outflows (SERSIO) rocket experiment 


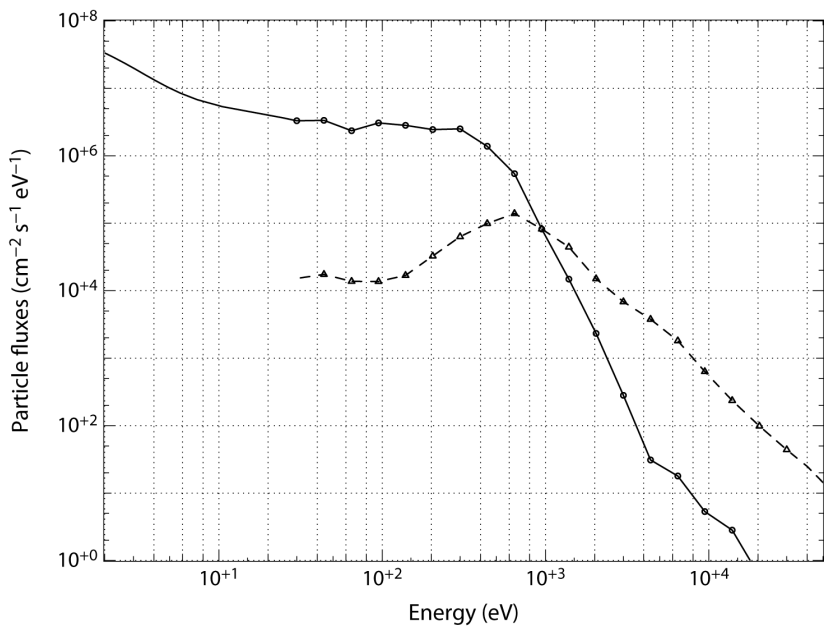

Fig. 2. Differential particle fluxes in units of $\mathrm{cm}^{-2} \mathrm{~s}^{-1} \mathrm{eV}^{-1}$ versus energy (in keV) and averaged over $30 \mathrm{~s}$ between 08:44:55 and 08:45:25 UT as measured by DMSP. Black circles represent the particle electron flux distribution and black triangles the proton flux distribution. Though the proton fluxes at their peak are nearly 100 times less intense, their average energy is twice as high, i.e. $1 \mathrm{keV}$ vs. $400 \mathrm{eV}$ for the electrons. Each spectrum is extrapolated at high and low energies (solid and dashed lines for electrons and protons respectively), where they show a behaviour very different from a Maxwellian distribution.

contributed by Dartmouth College, Cornell University, Universities of Oslo and Svalbard (UNIS), Nagoya University, University of Southampton and University of Leicester. The rocket was launched at 08:57 UT, roughly $10 \mathrm{~min}$ after a DMSP satellite pass. Therefore the rocket results will not be considered here. This day was one of the most active in January 2004. Two C-class CMEs, hurled into space near sunspot 540 in the Earth's direction, were observed by SOHO in less than $48 \mathrm{~h}$ prior to the measurements. A stream of fast solar wind $\left(\sim 700 \mathrm{~km} \mathrm{~s}^{-1}\right)$ then led to a geomagnetic storm which began to develop at 01:30 UT on 22 January 2004 (strong $B_{z}>0$ of $\sim 20 \mathrm{nT}$ ). Near the L1 point in the solar wind upstream of the Earth, between 00:00 UT and 10:00 UT, the ACE spacecraft (Chiu et al., 1998), showed interplanetary magnetic field conditions typical of lobe reconnection configurations, with $B_{z}$ mostly positive and strong $B_{y}<0$, which lasted for the entire period considered here. According to ACE, the CME reached the spacecraft around 01:00 UT, when the solar wind velocity jumped from 450 to nearly $700 \mathrm{~km} \mathrm{~s}^{-1}$. For such a velocity, there is a time delay of $45 \mathrm{~min}$ from ACE to the Earth's magnetopause. Several $B_{z}$-negative episodes appeared between 05:00 and 08:00 UT, lasting half an hour on average, which were correlated with variations in the ground-based magnetograms. At 08:00 UT, a strong $B_{z}$-negative flow was recorded by ACE, which was responsible for the strong perturbation of the geomagnetic field seen in the Longyearbyen magnetogram one hour later. At the same time, all-sky cameras and spectrometers recorded large enhancements indicative of enhanced precipitation fluxes. The $630.0 \mathrm{~nm}$ red and $557.7 \mathrm{~nm}$ green emission line intensities increased by factors up to 3 , a tendency observed as well for $\mathrm{H}_{\alpha}$ spectra.

The ground-based magnetograms, recorded at Longyearbyen, Ny-Ålesund and Troms $\emptyset$, and maintained at the Troms $\varnothing$ Geophysical Observatory, showed very sharp variations of all three magnetic components from 01:30 UT throughout the day with a very rapid variation around 09:00 UT. The decimetric solar index $F_{10.7}$ was 130 . The magnetic planetary index showed important variations over a few days before the event, and culminated in $A p=130$ at 09:00 UT with a daily average of 60. Because the event was during the winter with a solar zenith angle of $\chi=98^{\circ}$, hardly any photoionisation was present.

\subsection{Ionospheric measurements}

\subsubsection{DMSP F13 data}

The Defense Meteorological Satellite Program (DMSP) operated by the Air Force is a programme involving numerous spacecraft orbiting the Earth since the 1960s in Sunsynchronous near-polar orbits. DMSP F13 was launched in 1995 in a $800 \mathrm{~km}$-altitude orbit and carries among other instruments a precipitating electron and ion spectrometer SSJ/4 sampling the range $30 \mathrm{eV}-30 \mathrm{keV}$. DMSP F13 closest approach to the ESR $32 \mathrm{~m}$ beam was at 08:45:10 UT. The coordinates of the spacecraft were geographic latitude $77.5^{\circ}$ and longitude $9.4^{\circ}$, i.e. more than $6^{\circ}$ in longitude away from the ESR location, corresponding to roughly $150 \mathrm{~km}$ at this latitude when projected to an altitude of $100 \mathrm{~km}$. Therefore the DMSP precipitating fluxes are not an exact measurement of the situation right over the ESR.

The proton fluxes were averaged over $30 \mathrm{~s}$ centred on 08:45:10 UT (Fig. 2) and extrapolated at low energies, i.e. below $30 \mathrm{eV}$. Below $30 \mathrm{eV}$, the shape of the electron spectrum is becoming strongly non-Maxwellian. We use here a shape for the extrapolation increasing slowly with the decreasing energies (of the form $\alpha \mathrm{e}^{-\gamma}$ ) to reach a second maximum at $1 \mathrm{eV}$, a curve shape corroborated by satellite and rocket measurements (Hardy et al., 1985; Winningham and Heikkila, 1974). This average over $30 \mathrm{~s}$ was also applied to the electron distribution for the sake of consistency. Numerically, we reach an equilibrium in TRANS4 by introducing a constant precipitation throughout the run and not by turning it on and off again in a short time.

Two peaks are present in the electron flux distribution, the largest one at very low energies $(<10 \mathrm{eV}$ nearly reaching $10^{8} \mathrm{~cm}^{-2} \mathrm{~s}^{-1} \mathrm{eV}^{-1}$ ), the other centred around $400 \mathrm{eV}$ reaching $2 \times 10^{6} \mathrm{~cm}^{-2} \mathrm{~s}^{-1} \mathrm{eV}^{-1}$. According to the model, above $10 \mathrm{keV}$, the flux of precipitating particles is too small to contribute significantly to the ionisation. 


\subsubsection{ESR and optical observations}

The EISCAT Svalbard Radar (ESR) is situated at $\left(78.15^{\circ} \mathrm{N}\right.$, $\left.16.03^{\circ} \mathrm{E}\right)$ geographic coordinates. The ESR facility is composed of two antennae, one fixed dish $42 \mathrm{~m}$ in diameter and aligned along the $\boldsymbol{B}$-field, the other antenna being steerable and $32 \mathrm{~m}$ in diameter. In the following study, only the 32 $\mathrm{m}$ antenna is used. The original data recorded by the ESR run on 22 January 2004 show multiple occurrences of naturally enhanced ion acoustic lines which corrupt the standard EISCAT analysis (using the GUISDAP software) in the topside ionosphere. The ESR data were therefore reprocessed with a technique expounded in Ogawa et al. $(2000,2006)$. It is also known that ion composition and collision frequency models have high influences on the output parameters, in particular ion and electron temperatures below $300 \mathrm{~km}$ altitude. We therefore used ion and electron temperatures above $300 \mathrm{~km}$ for quantitative comparison between data and model. The 32-m steerable dish was pointed at $70.8^{\circ}$ elevation to the west (azimuth $261.1^{\circ}$ ) of Longyearbyen. The coordination period is preceding a much more active one where electron densities gradually build up to $10^{11} \mathrm{~m}^{-3}$ with a main peak situated around $300 \mathrm{~km}$. At the coordination time span, the $e^{-}$and ion temperatures are significantly high, with very high ion temperature recorded around $400 \mathrm{~km}\left(T_{i} \sim 3000 \mathrm{~K}\right)$ in comparison to the electron temperature $\left(T_{e} \sim 2000 \mathrm{~K}\right.$ at the same altitude). High $T_{i}$ can be interpreted as an evidence for the presence of strong electric fields in the lower ionosphere through frictional heating (see the review of Brekke and Kamide, 1996). These electric fields are taken into account in our modelling.

2.2.3 The Ebert-Fastie spectrometer data: the $\mathrm{H}_{\alpha}$ and $\mathrm{H}_{\beta}$ lines

Two Ebert-Fastie spectrometers were running at the time of the coordination, one located at Nordlysstasjonen (Adventdalen) near Longyearbyen, called Green, and the other situated at $\mathrm{Ny}$-Ålesund called Black (Holmes et al., 2007 ${ }^{1}$ ). The focal length of the Green spectrometer is $1 \mathrm{~m}$ and it measures the auroral $\mathrm{H}_{\beta}$ line $(486.1 \mathrm{~nm})$. The Black spectrometer, of focal length $0.5 \mathrm{~m}$, is calibrated for the $\mathrm{H}_{\alpha}$ line $(656.3 \mathrm{~nm})$. The Full Width at Half Maximum (FWHM) of the instruments spans from $4.2 \AA$ (Black) to $3.1 \AA$ (Green). Unfortunately, at the time of the coordination with DMSP, the sky was covered with a thin cloud layer, which smeared out the observed spectral lines. Moreover, the presence of a cloud cover precludes the possibility of comparing directly the measured and modelled intensities. The $\mathrm{H}_{\alpha}$ spectra have been averaged over 2 cycles of $1 \mathrm{~min}$ each in order to improve the signal-to-noise ratio. At around $6560 \AA$, a broad peak cor-

\footnotetext{
${ }^{1}$ Holmes, J. M., Kozelov, B., Sigernes, F., Lorentzen, D. A., and Deehr, C. S.: Dual site observations of dayside Doppler-shifted hydrogen profiles: preliminary results, Can. J. Phys., submitted, 2007.
}

responding to the $\mathrm{H}_{\alpha}$ line is seen, indicating a slight Doppler blue shift in the peak of $2 \AA$ at the most, i.e. a line-of-sight velocity of $100 \mathrm{~km} \mathrm{~s}^{-1}$. This shift is weak in comparison to commonly observed blue shifts which can reach $500 \mathrm{~km} \mathrm{~s}^{-1}$ (Søraas et al., 1994). This low value is an indication of softenergy proton precipitation. Moreover an important red shift can be seen, its half width extending $7 \AA$ from the centred wavelength $\lambda_{0}$ towards smaller wavelengths. This red shift cannot be attributed only to instrumental broadening.

As the $630.0 \mathrm{~nm}$ red line, routinely used to calibrate the spectra, is situated spectroscopically far away from the $\mathrm{H}_{\alpha}$ line it is sometimes better to recalibrate manually the spectrum around $6500 \AA \AA$ through $\mathrm{OH}(6-1)$ rotational bands which show features at 6500,6580 and $6600 \AA$. The $\mathrm{OH}$ contribution has been subtracted from the $\mathrm{H}_{\alpha}$ line in the processed data by using a modelled $\mathrm{OH}$ spectrum based on Sigernes et al. (2003) and described in Holmes et al. (2007) ${ }^{1}$. Because of scattered sunlight approaching local noon, the $\mathrm{H}_{\beta}$ profiles obtained were superimposed on a background containing significant Fraunhofer absorption near the $\mathrm{H}_{\beta}$ rest wavelength. Although methods currently exist to account for this twilight component of the background (Robertson et al., 2006; Borovkov et al., 2005), the profiles were not chosen for analysis.

\subsection{Comparison between measurements and computations}

\subsubsection{Optical data: modelled parameterization of the im- pact of protons}

\section{$H_{\alpha}$ and $H_{\beta}$ integrated zenith spectral profiles}

We investigate here the effects of the angular redistributions on the overall shape of the spectral lines. Several cases are studied, involving no angular redistributions, magnetic mirroring effects, angular redistributions due to elastic scattering, and combined magnetic/collisional angular redistributions. Angular redistributions will affect the red-shifted part of the spectrum, while the blue-shifted peak position will be unchanged, because it arises only from downward $\left(\mathrm{H}^{+}, \mathrm{H}\right)$ fluxes. However the peak intensities will change according to the upward supplementary contribution involved, observing a slight decrease as the impact of angular redistributions becomes more important. In the event we are studying, we expect the collisions to play an important role since the energies involved in the main precipitation are low. This sensitivity aspect was already pointed out in previous works, either experimental (Gao et al., 1990) or theoretical (Basu et al., 1993; Galand et al., 1998). Laboratory measurements on differential cross sections have shown the energy dependence of angular redistributions as well (Fleischmann et al., 1967; Newman et al., 1986). The flexibility that the model allows concerning these parameters is investigated through the use of different angular redistribution functions (Maxwellian distribution and Rutherford cross section) for charge-changing 
reactions and elastic scattering. The magnetic mirroring issue is also addressed, though its contribution is expected to be weak for incoming proton fluxes with an isotropic angular distribution, which is assumed to be the case here (see the early work of Bagariatskii (1958a, b) and the recent confirmation of Galand et al., 1998). At a given pitch angle a particle of lower energy will correspond to a smaller Doppler shift.

The input proton fluxes are taken from DMSP at 08:45 UT on 22 January 2004. They have an average energy of $1 \mathrm{keV}$ with a flux of $1.5 \mathrm{erg} \mathrm{cm}^{-2} \mathrm{~s}^{-1}$, i.e. $9.34 \times 10^{11} \mathrm{eV} \mathrm{cm}^{-2} \mathrm{~s}^{-1}$. The neutral atmosphere is given by the model MSIS-90 (Hedin, 1991) and O densities are divided by 2 to be more representative of a high latitude thermosphere (Lilensten et al., 1996).

\section{Without angular redistributions}

The spectrum, plotted in Fig. 3a, is simple: no red shift is observed, while the blue shift peak is situated around $2.8 \AA$ short of the centred line with an intensity reaching $2 \times 10^{6} \mathrm{~cm}^{-2} \mathrm{~s}^{-1} \AA^{-1}$. This blue shift corresponds to a parallel velocity of $127 \mathrm{~km} \mathrm{~s}^{-1}$, which is very slow in comparison to Doppler shifts commonly measured in proton events, reaching velocities up to three times as large (e.g. Søraas et al., 1974; Lanchester et al., 2003). This first result is consistent with the spectral shifts recorded from the ground in $\mathrm{Ny}-$ Ålesund. Incoming protons of low mean energies $(\sim 1 \mathrm{keV})$ precipitating in the topside ionosphere are responsible for such slight Doppler shifts, as already shown by the DMSP differential particle fluxes.

As the proton fluxes are contributing on average less than the hydrogen fluxes to the overall emission rate, they are only responsible for $5 \%$ of the total emission rate at the peak around $6560 \AA$. However this tendency reduces at large Doppler shifts $(30 \AA)$ where the proton fluxes become larger than the hydrogen ones, resulting in a majority contribution of precipitating $\mathrm{H}^{+}$that have then been neutralized. This phenomenon comes intrinsically from the distribution of equilibrium charge fractions for $\mathrm{H}^{+}$and $\mathrm{H}$, which states the proportion of each charge state as a function of energy. They are simply expressed as the ratio between electron capture cross sections (respectively ionization-stripping) and the total charge-changing collision cross section for each species $\mathrm{N}_{2}, \mathrm{O}_{2}$ or O (see e.g. Rees, 1982). At low energy, hydrogen atoms will dominate the composition, while protons will be the major species above a few tens of $\mathrm{keV}$. This preliminary statement will be examined in more details in the case of collisional angular redistributions.

Impact of magnetic mirroring on spectral line profiles and altitude of mirror point

The magnetic mirroring effect, by reflecting charged particles upwards produces a red-shifted tail in the spectral distri- bution (Fig. 3b). The computed intensity drops sharply near the centred wavelength (around $10^{3} \mathrm{~cm}^{-2} \mathrm{~s}^{-1} \AA^{-1}$ ). If fitted by a bi-Gaussian-type distribution following the method explained in Lummerzheim and Galand (2001), the full width at half maximum on the red side reaches $2 \AA$, a value inside the instrumental broadening, while on the blue side, it reaches $10 \AA$. When we look at the spectra recorded at NyAllesund for this event, we can see clearly the red wing of the line, which is almost symmetric with a 9- $\AA$ wide red tail at half maximum. This confirms that the magnetic mirroring cannot explain solely the shapes observed for the $\mathrm{H}_{\alpha}$ line. This outcome is to be linked to the region where the magnetic mirroring becomes effective; it mainly acts at higher altitudes, converting particles having high pitch angles to particles with lower pitch angles, hence the change of slope in the spectral distribution on the red side (Lorentzen et al., 1998; Kozelov, 1993). The upward fluxes are generated by magnetic mirroring at higher altitudes, typically in the upper $\mathrm{F}_{1}$ region, and, for $10 \mathrm{keV}$ protons, are well above the energy deposition region usually situated between 110 and $130 \mathrm{~km}$, where the main blue-shifted peak of the Balmer lines occurs induced by downward fluxes. In our case, the mean energies involved are much smaller ( $1 \mathrm{keV}$ with a large high energy tail as shown in the DMSP data) and the energy deposition peak occurs between 140 and $150 \mathrm{~km}$, making it more sensitive to magnetic mirroring effects. For an isotropic initial distribution, the penetration depth for $1 \mathrm{keV}$ protons precipitating into the ionosphere is typically around $150 \mathrm{~km}$, which coincides with the altitude computed by TRANS4 where magnetic mirroring begins to act. The effect of upward fluxes arising from magnetic reflection becomes significant at the deposition peak and makes the red-shifted tail grow with increasing altitude (Fig. 4). From $140 \mathrm{~km}$ up to $600 \mathrm{~km}$ the magnetic mirroring populates preferentially the longer wavelengths, and the volume emission rate reaches $10^{-7} \mathrm{~cm}^{-3} \mathrm{~s}^{-1} \AA^{-1}$ at $6570 \AA$. In comparison, at the same Doppler shift the volume emission rate at $128 \mathrm{~km}$ drops to $10^{-8} \mathrm{~cm}^{-3} \mathrm{~s}^{-1} \AA^{-1}$, while it becomes completely negligible at lower altitudes due to the complete energy degradation of proton fluxes at these altitudes.

With increasing altitude, two peaks on either side of $\lambda_{0}$ are appearing. For $90^{\circ}$ pitch-angles, i.e. near $\lambda_{0}$, both high and low energies contribute to the emission rates. But, when the altitude increases, so do the high energy fluxes, which become predominant over the low-energy ones above $200 \mathrm{~km}$. These high-energy fluxes are responsible for an overall enhancement of the emission, a raise particularly visible near $\lambda_{0}$ where in contrast only low-energy fluxes contribute to the emission rates, producing a sudden drop in intensity. We must also notice that high red shifts are created by highenergy particles having small pitch angles, a consequence of the propagation of upward fluxes in the upper part of the ionosphere. However, to account for more symmetric shapes of the observed spectral line which the magnetic mirroring cannot explain, we will now study the effect of collisions on 
(a)

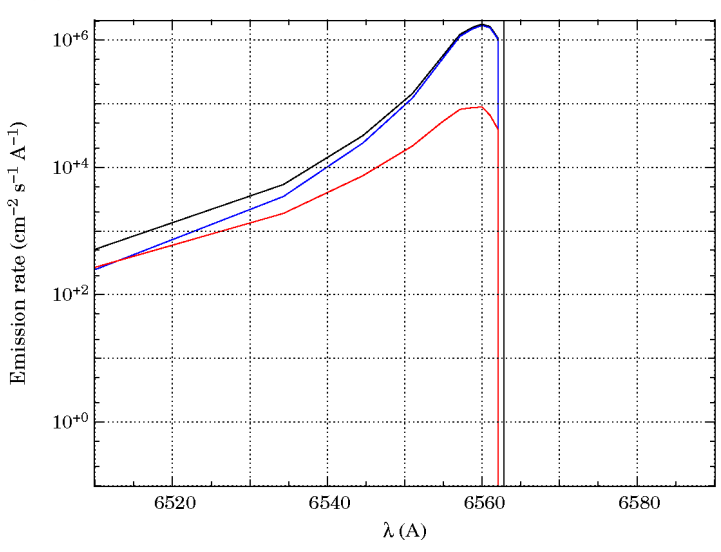

(c)

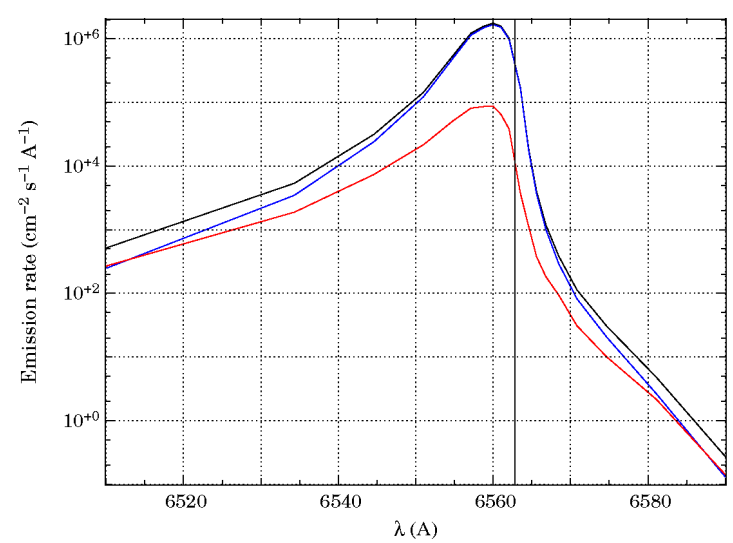

(e) Elastic seattering - charge-changing reactions

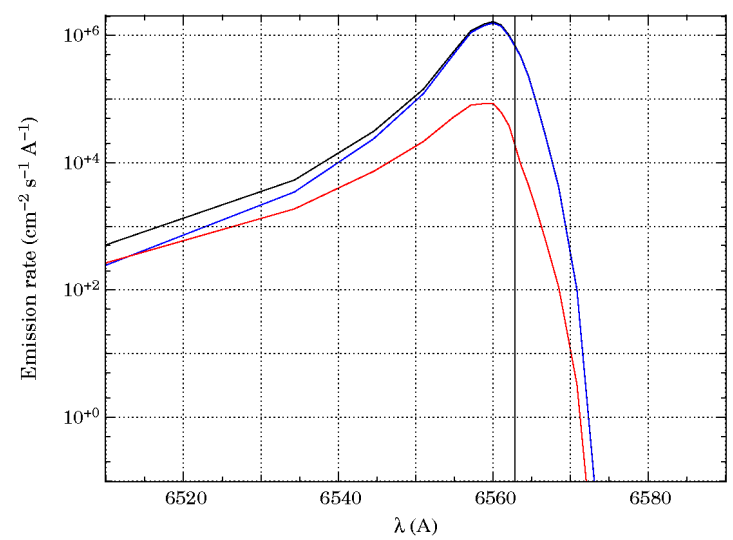

(b)

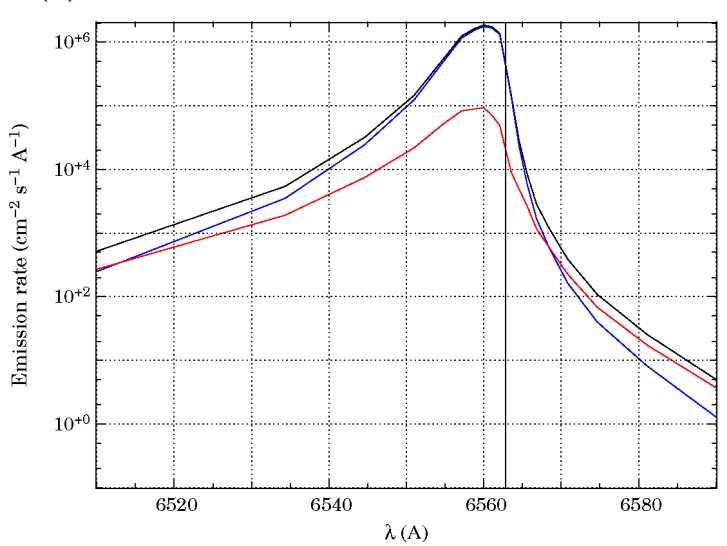

(d) Elastic scattering - charge-changing reactions



(f) Magnetic mirroring and collisions

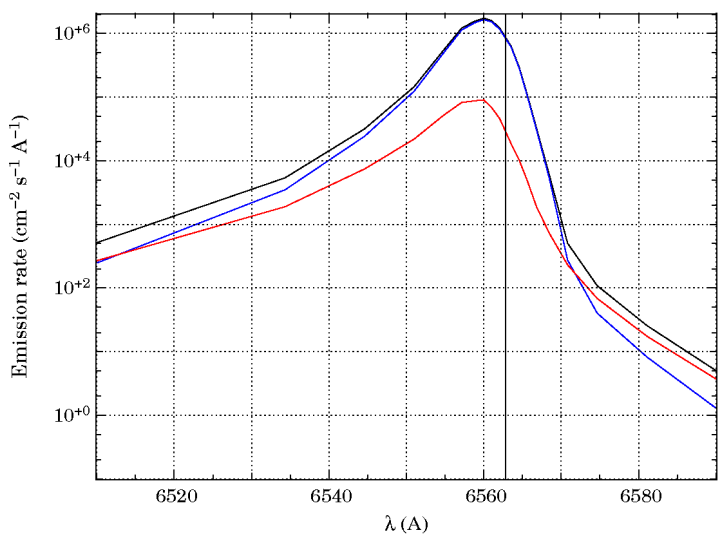

Fig. 3. $\mathrm{H}_{\alpha}$ spectra computed by TRANS4 with initial DMSP proton fluxes, drawn together with the centred wavelength $\lambda_{0}=6562.8 \AA$ A The overall integrated emission rate is shown in black, and the contribution from the hydrogen flux and the proton fluxes are shown in blue and red, respectively. In panel (a), the results without angular redistributions of magnetic or collisional origins are shown. Only a $3-\AA \AA$ blueshifted peak is seen. Panel (b): with magnetic mirroring, a narrow red-shifted tail appears which extends to a few Angströms off the centred wavelength. Panels (c) and (d): collisional angular redistributions make the line more symmetric. Here different configurations are shown for both phase functions of elastic and charge-changing scattering: Maxwellian distributions with successively $\sigma=0.05$ (c) and $\sigma=0.20$ (d), and the more accurate approach of Rutherford (e). The spreading of the line with increasing angular scattering is clearly visible. Panel (f): combined contributions for magnetic mirroring effects and elastic scattering using Rutherford formula. 


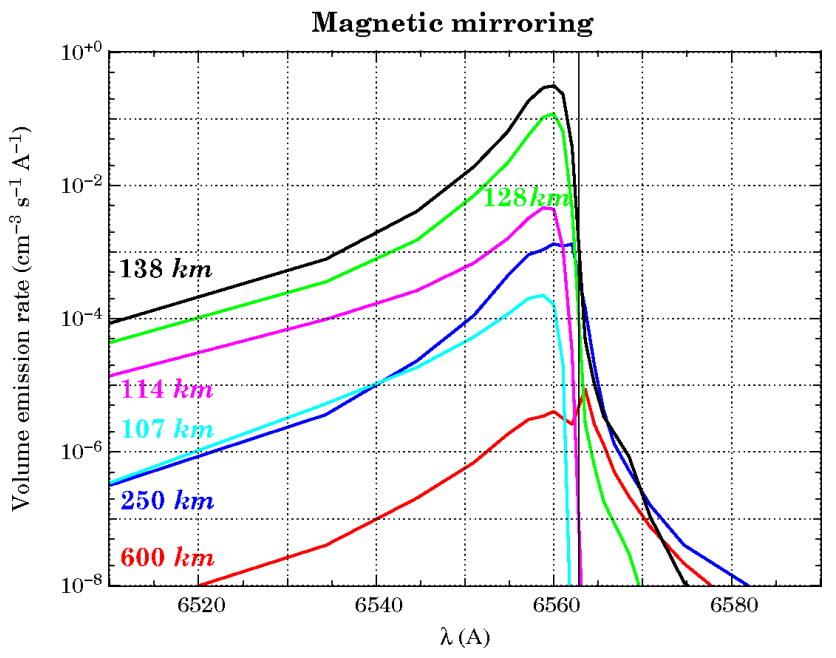

Fig. 4. $\mathrm{H}_{\alpha}$ volume emission rates in $\mathrm{cm}^{-3} \mathrm{~s}^{-1} \AA^{-1}$ computed by TRANS4 with magnetic mirroring at $107 \mathrm{~km}$ (cyan), $114 \mathrm{~km}$ (magenta), $128 \mathrm{~km}$ (green), $138 \mathrm{~km}$ (black), $250 \mathrm{~km}$ (blue) and $600 \mathrm{~km}$ (red). The effective maximum emission is encountered at around $140 \mathrm{~km}$, which is consistent with particles of mean energy ranging between 1 and $2 \mathrm{keV}$. Only magnetic mirroring effects are considered here.

the overall shape of the lines, as shown in Fig. 3.

\section{Study of collisions for charge-changing and elastic collision reactions}

A few cases have been considered which are shown in Fig. 3c and $\mathrm{d}$ in order to show the influence of collisional angular redistributions on the shape of spectral lines, which will serve as groundwork for the comparison between data and the model in Sect. 1.3. Not surprisingly, the shape of the lines can become dramatically sensitive to collisional redistributions, playing a larger role than magnetic mirroring. A real modulation of the red-shifted part can be performed and is very much dependent on the phase functions chosen to account for this mechanism. A Maxwellian distribution with a standard statistical deviation $\sigma$ ranging between $5 \%$ and $20 \%$ was first chosen and the results are shown in Figs. 3c and $\mathrm{d}$. The red-shifted tail broadens significantly between the two cases, from $2 \AA$ to $7 \AA$, a value that approximates the blue-shifted part of the line. For $\sigma=5 \%$ on Fig. 3c, the full width at half maximum of the right side of the spectrum is comparable to that of the mirroring effect, i.e. 1 to $2 \AA$. In comparison, this value can extend up to $8 \AA$ in the extreme case of a Maxwellian distribution of $\sigma=20 \%$ (Fig. 3d), which indicates that when choosing a wide angular redistribution due to collisions, computed Doppler shifts can become consistent with the measurements. Compared to magnetic mirroring, collisional angular redistributions play the major role at least at low Doppler shifts in the creation of the observed spectrum, a conclusion that was previously put forward to ac-

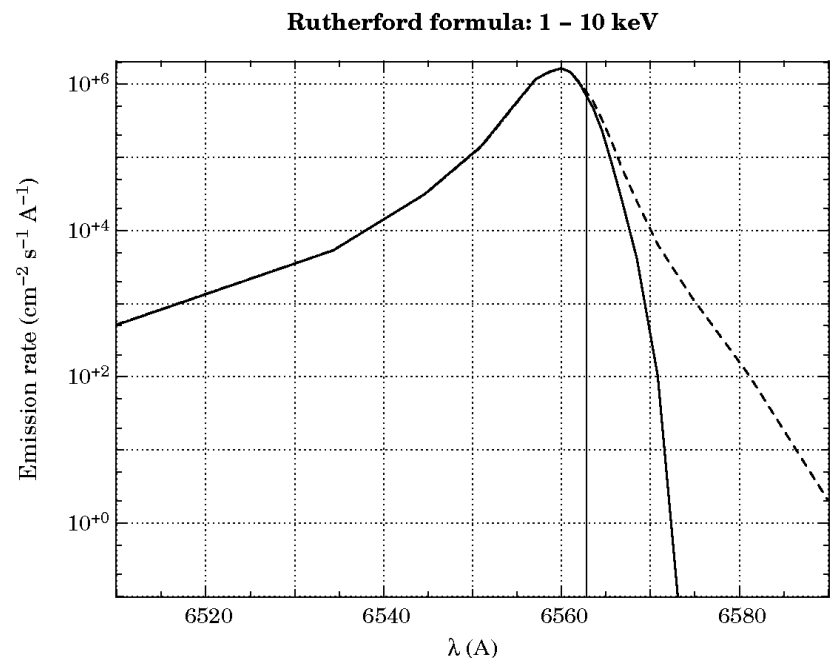

Fig. 5. $\mathrm{H}_{\alpha}$ emission rate Doppler profile computed for collisional angular redistributions applied successively below $1 \mathrm{keV}$ (solid line) and below $10 \mathrm{keV}$ (dashed line). The Rutherford formula is used. One can see the red wing extend significantly in amplitude when angular redistributions below a higher threshold are included.

count for $\mathrm{H}_{\beta}$ lines (Lanchester et al., 2003). In this case, the line can become completely symmetric with a second peak appearing at longer wavelengths near $6565 \AA$. This is an indication that strong fluxes are generated by particles having frequently changed pitch-angles and energies because of the increasing number of collisions at low altitudes, while at $\lambda_{0}$, only a few particles remain unchanged.

The angular redistribution due to collisions appears to make the fluxes more isotropic in the lower ionosphere, while at high altitudes, changes in pitch angles and energy occur less often because of the decreasing atmospheric density. Soft protons are more likely to be sensitive to collisions; hence the choice of the phase function is a crucial issue. If we increase the number of angles accessible for a given incoming particle colliding with a neutral species, both proton and hydrogen upward fluxes generated will be strongly enhanced, especially since collision cross sections (and charge-changing reaction cross sections even more so) remain high under $10 \mathrm{keV}$. Forward scattering is assumed for particles having energies above $1 \mathrm{keV}$, but this limit might be increased to higher energies depending on the event chosen. This physical limit will modulate the extent of the red wing to higher energies as shown in Fig. 5 for a threshold of $10 \mathrm{keV}$ instead. The blue part of the spectrum is unchanged but the red wing is more raised which confirms the sensitivity of the results to the Rutherford parameter. Including redistributions at high energies can have a dramatic effect and may change the position of the peak in the case of high-energy proton precipitation. This was already emphasized in Lanchester et al. (2003) in the case of $\mathrm{H}_{\beta}$, and we can now extend these conclusions to $\mathrm{H}_{\alpha}$. 


\section{Combined effects and detail of the impact of $\left(\mathrm{H}, \mathrm{H}^{+}\right)$fluxes on the overall distribution}

We now compare the spectral $\mathrm{H}_{\alpha}$ data with the model outputs including magnetic mirroring and Rutherford collisional angular redistributions. These results are shown in Fig. 6. To take into account the spectrometer's resolution, the profiles produced by the models are convolved with the instrumental function which is taken as a triangle function with different widths at half maximum, spanning from the nominal FWHM (around $4 \AA$ ) to larger values ( $8 \AA$ ). Generally, the geometry of the entrance and exit slits of an Ebert-Fastie spectrometer produces a trapezoidal instrumental function. When the widths of both of the slits are matched, the function becomes triangular (Lerner and Thevenon, 1988). By degrading artificially the resolution of the instrument, we show that the model can reproduce the measurements very well. In Fig. 6, we present the first comparison between the model, drawn in black solid line, including angular redistributions (magnetic mirroring and Rutherford scattering applied below $1 \mathrm{keV}$ ) and the spectral intensity recorded by the Black spectrometer (noisy curve). The narrow nominal profile of the spectrometer cannot explain by itself the differences observed, and we have to increase substantially the width of the instrumental function to get profiles similar to those recorded by the instrument. We have degraded the resolution of the instrument, which can be interpreted as an estimate of the thin cloud-coverage on the hydrogen lines or an inaccurate original determination of the instrumental bandpass.

The main results of this approach are shown in Fig. 7, where emission rates and volume emission rates for given altitudes are plotted. Magnetic mirroring becomes important at higher altitudes and is particularly significant at high Doppler shifts, while the angular distributions due to elastic and charge-changing reactions reach their full power at lower altitudes and for red shifts between 1 and $8 \AA$. The ratios of emission rates drawn in Fig. 7 (right) illustrate this double impact and can be seen as a mix of magnetic and collisional redistributions. The red wing reveals a greater impact of hydrogen atoms at smaller red shifts as in the Rutherford scattering case. For spectral shifts to longer wavelengths, the protons play the major role in the emission, matching the conclusions that were drawn in the magnetic mirroring case.

\section{Results for $H_{\beta}$}

Following the validation of our approach in terms of angular redistributions and spectral widths, we show in Fig. 8 the emission rates expressed in $\mathrm{cm}^{-2} \mathrm{~s}^{-1} \AA^{-1}$ for $\mathrm{H}_{\beta}$. The overall intensity is smaller than for $\mathrm{H}_{\alpha}$ by a factor 2 , which is consistent with the preliminary modelling of Galand (1996) and Galand et al. (2004). Both collisions and magnetic mir-

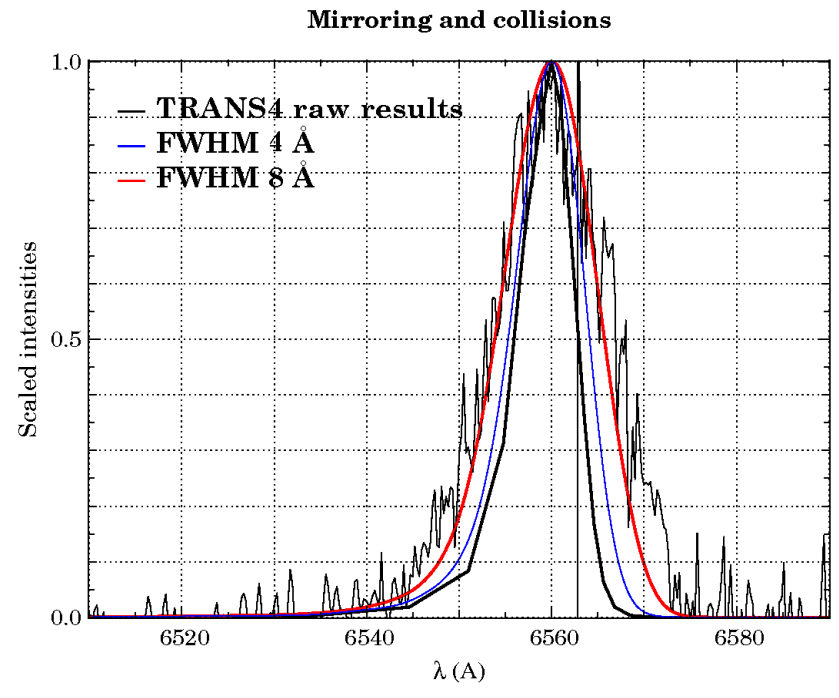

Fig. 6. First out-of-the-box comparison between spectral $\mathrm{H}_{\alpha}$ data recorded at Ny-Ålesund (discontinuous line) and the model (black line). A triangle function of FWHM=4 $\AA$ was first chosen for the instrumental function, which was then convolved with the raw results from the model. The resulting intensity is drawn in blue. When using a triangle function of $\mathrm{FWHM}=8 \AA$, the model yields the resulting line intensity drawn in red, which matches the measurements quite well.

roring are easily seen, the former at smaller red shifts the latter at bigger red shifts.

\subsubsection{Comparison to radar data and validation of the ap- proach}

\section{ESR measurements}

Figure 9 shows the electron density height profiles produced by the model in the case of combined electron-proton precipitation versus the electron densities recorded by ESR averaged here over $20 \mathrm{~min}$. This mean value is then representative of the ionospheric conditions around the coordination time at 08:45 UT while the DMSP satellite was at $800 \mathrm{~km}$. The ESR error bars are drawn at altitudes higher than $300 \mathrm{~km}$.

The temperatures (not shown here) exhibit a typical electric-field event behaviour. The ion temperature reaches a value of $3000 \mathrm{~K}$ at $400 \mathrm{~km}$ which is larger than the electron temperature $(2000 \mathrm{~K})$. This effect implies modifications in the ion composition around the F1 layer (Lathuillère and Kofman, 2006), which makes it meaningless to compare the IS temperatures with TRANS4 outputs. However, the electron densities are deduced from fitting of the incoherent scatter spectrum and are thus useable for our comparison. Ion velocities obtained by the ESR 32-m dish were $-600 \mathrm{~m} \mathrm{~s}^{-1}$ at $220 \mathrm{~km}$ altitude at 08:45 UT. The high ion velocity indicates that a strong eastward flow at a speed of $1500 \mathrm{~m} \mathrm{~s}^{-1}$ occurred near Longyearbyen. The $\boldsymbol{E} \times \boldsymbol{B}$ drift velocities derived from 

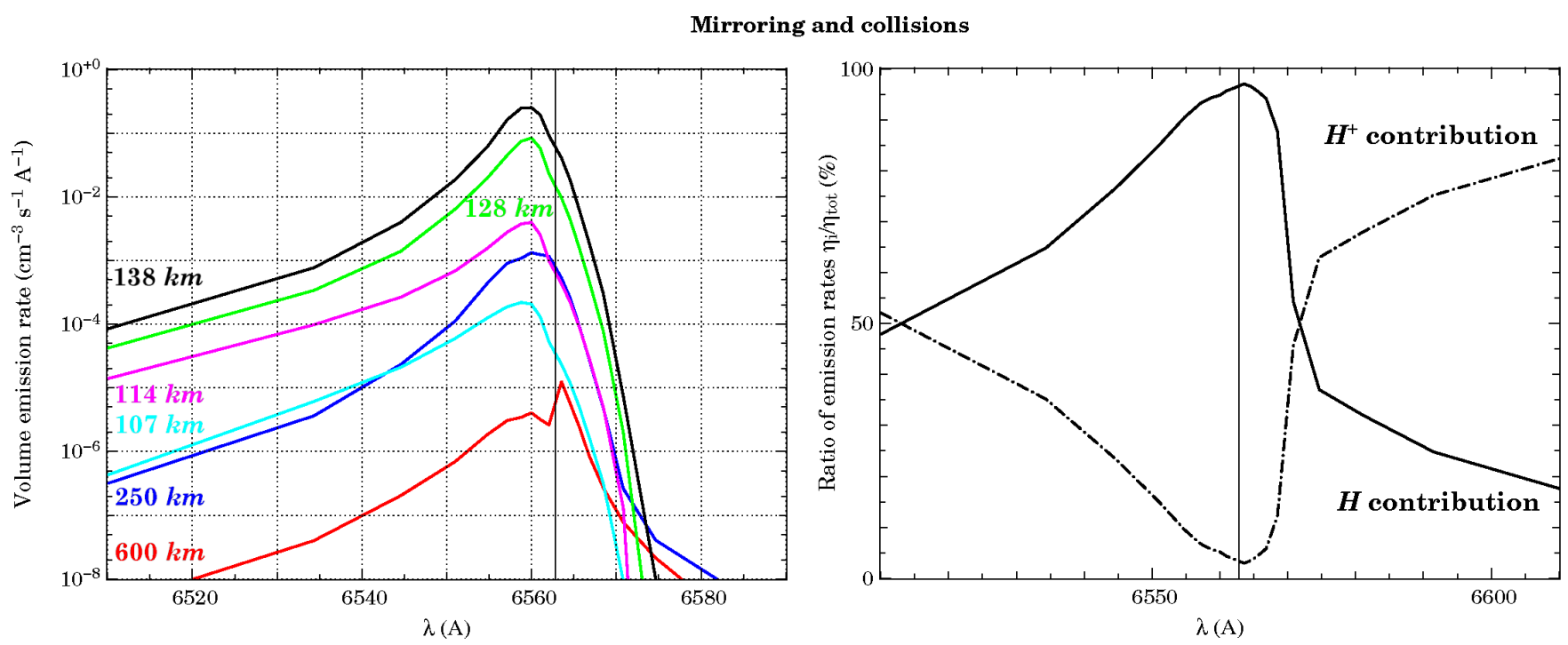

Fig. 7. $\mathrm{H}_{\alpha}$ spectra yielded by TRANS4 when taking into account angular redistributions of both magnetic and collisional origins under Rutherford's approximation for the phase function. The left panel is the detail of altitude contributions to the total volume emission rate. The same colour code as in Fig. 4 is used: 107 km (cyan), 114 km (magenta), 128 km (green), 138 km (black), $250 \mathrm{~km}$ (blue) and $600 \mathrm{~km}$ (red). In the right panel, the ratio of the contributions of proton (dash-dot) and hydrogen (solid line) to the total $\mathrm{H}_{\alpha}$ emission rate is plotted.

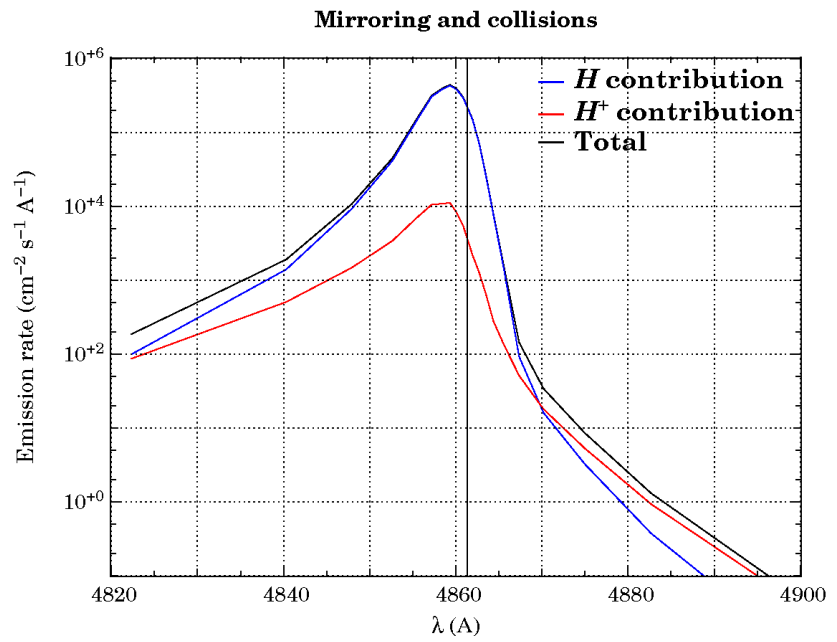

Fig. 8. $\mathrm{H}_{\beta}$ emission rates including angular redistributions of magnetic and collisional origins. In blue the hydrogen contribution to the emission is plotted, and in red the proton contribution.

the ESR measurements correspond to a first estimate of the electric field of $60-80 \mathrm{mV} / \mathrm{m}$ (not shown here). When comparing the direct model outputs with the incoherent scatter temperature, it results in a more accurate value of $65 \mathrm{mV} / \mathrm{m}$, which was used in the density computations. Because of the strong electric field encountered, we expect an electron density depletion in the $\mathrm{F}$ region ionosphere compared to the case where no electric field is present, and the effect is also included in the model.

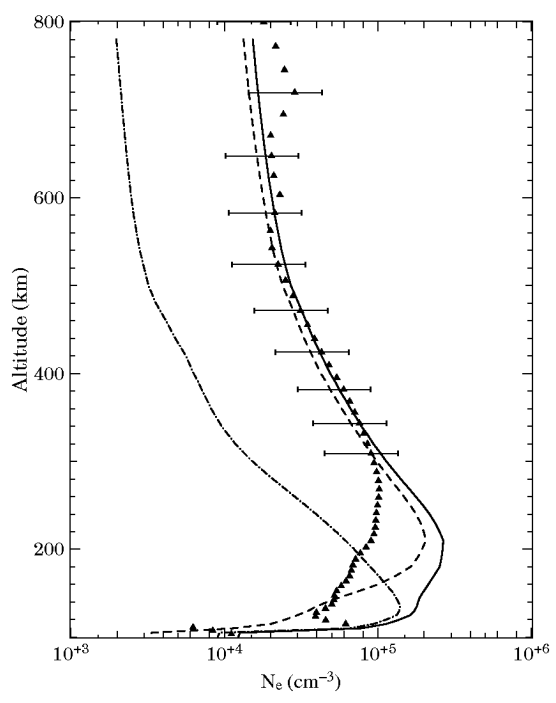

Fig. 9. Contribution of precipitating electrons (dash line) as a single source in the code and of proton precipitation (dash-dotted line) as a single source in the code to the total electron density (black solid line). The model's outputs are drawn versus the ESR averaged measured electron densities, which are indicated with black triangles.

Though below $250 \mathrm{~km}$ the computed densities are larger than the measured densities by a factor three, a perfect match is found between 300 and $800 \mathrm{~km}$. This difference is no surprise. As emphasized in the description of the data (Sect. 2.2), we expect the model to be accurate in the range $600-800 \mathrm{~km}$. The electron and proton fluxes recorded by 
DMSP are indeed representative of the region probed by EISCAT at these altitudes at the coordination time. However, in the first few hundred kilometres along the ESR 32-m beam, we are geographically and magnetically far from the conditions traversed by the satellite. The conditions were very different from one probed region to another. In the all-sky camera images (not shown here, see Simon, 2006, or Lorentzen et al., 2007), the region probed at $100 \mathrm{~km}$ by the ESR beam was less active than the upper regions which were also further away from the radar site in the horizontal direction. This is also confirmed by the model and, as shown in Fig. 9, a factor of three in electron densities is required at low altitudes to account for the data.

In the same plot, we show an estimate of the electron densities due to the two sources. In one run, we turn on only the electron precipitation and in a second run only the proton precipitation. Although the system is not totally linear because of the chemistry and fluid transport, this gives an idea of the contribution of each source. In particular, it shows that the proton precipitation is responsible for the electron densities at low altitudes (around $110 \mathrm{~km}$ ) while the electron precipitation creates electron densities at altitudes above $170 \mathrm{~km}$.

\section{Conclusion}

This work presents the first coupled numerical ionospheric code that dynamically solves the fluid, electron and proton kinetic equations. It allows retrieving macroscopic parameters such as the electron density or Balmer hydrogen emission lines as well as microscopic parameters such as the distribution function and electron fluxes. We have shown the results compared to a set of experimental data during a coordinated experiment (DMSP, ESR, spectrometer and all-sky cameras) situated in the cusp region. This allowed us to show the respective effects of collisions and magnetic mirroring on the transport of precipitating protons. We also showed that, in this event, protons were responsible for the low-altitude density peak and contributed up to $15 \%$ of the total ionisation above an altitude of $200 \mathrm{~km}$.

Acknowledgements. C. Simon would like to thank D. Lorentzen (University Centre on Svalbard UNIS, Norway) and F. Pitout (LPG, France) for their fruitful comments and discussions throughout the preparing of this work and the interpretation of data. The authors thank H. Opgenoorth (ESA ESTEC, the Netherlands) for his constructive advices on the original manuscript. We would like also to thank C. Deehr of the Geophysical Institute for having made available the $0.5 \mathrm{~m}$ Black spectrometer data and F. Sigernes (UNIS) who operated and maintained the instrument during the campaign 20032004. We are indebted to the director and staff of EISCAT for operating the facility and supplying the data. EISCAT is an International Association supported by Finland (SA), France (CNRS), Germany (MPG), Japan (NIPR), Norway (NFR), Sweden (NFR) and the United Kingdom (PPARC). Financial support has been provided by the Norwegian Research Council and AFOSR task 2311A5.
Topical Editor M. Pinnock thanks two referees for their help in evaluating this paper.

\section{References}

Bagariatskii, B. A.: The Influence of Proton Spiral Trajectories on the Doppler Profile of Auroral Hydrogen Lines, Sov. Astron., 2, 87-96, 1958a.

Bagariatskii, B. A.: The Zenith Angle Distribution Function of Auroral Protons, Sov. Astron., 2, 453, 1958b.

Basu, B., Jasperse, J. R., Robinson, R. M., Vondrak, R. R., and Evans, D. S.: Linear transport theory of auroral proton precipitation - A comparison with observations, J. Geophys. Res., 92, 5920-5932, 1987.

Basu, B., Jasperse, J. R., and Grossbard, N. J.: A numerical solution of the coupled proton-H atom transport equations for the proton aurora, J. Geophys. Res., 95, 19069-19078, 1990.

Basu, B., Jasperse, J. R., Strickland, D. J., and Daniell Jr., R. E.: Transport-theoretic model for the electron-protonhydrogen atom aurora. 1: Theory, J. Geophys. Res., 98, 21 517$21532,1993$.

Borovkov, L. P., Kozelov, B. V., Yevlashin, L. S., and Chernouss, S. A.: Variations of auroral hydrogen emission near substorm onset, Ann. Geophys., 23, 1623-1635, 2005, http://www.ann-geophys.net/23/1623/2005/.

Brekke, A. and Kamide, Y.: On the relationship between Joule and frictional heating in the polar ionosphere, J. Atmos. Terr. Phys., 58, 139-143, 1996.

Chakrabarti, S., Pallamraju, D., Baumgardner, J., and Vaillancourt, J.: HiTIES: A high throughput imaging echelle spectrograph for ground-based visible airglow and auroral studies, J. Geophys. Res., 106, 30 337-30 348, doi:10.1029/2001JA001105, 2001.

Chamberlain, J. W.: The Excitation of Hydrogen in Aurorae., Astrophys. J., 120, 360-366, 1954a.

Chamberlain, J. W.: On the Production of Auroral Arcs by Incident Protons., Astrophys. J., 120, 566-571, 1954b.

Chamberlain, J. W.: On a Possible Velocity Dispersion of Auroral Protons., Astrophys. J., 126, 245-252, 1957.

Chiu, M. C., von-Mehlem, U. I., Willey, C. E., Betenbaugh, T. M., Maynard, J. J., Krein, J. A., Conde, R. F., Gray, W. T., Hunt Jr., J. W., Mosher, L. E., McCullough, M. G., Panneton, P. E., Staiger, J. P., and Rodberg, E. H.: ACE Spacecraft, Space Sci. Rev., 86, 257-284, doi:10.1023/A:1005002013459, 1998.

Davidson, G. T.: Expected Spatial Distribution of Low-Energy Protons Precipitated in the Auroral Zones, J. Geophys. Res., 70, 1061-1068, 1965.

Deehr, C. S., Lorentzen, D. A., Sigernes, F., and Smith, R. W.: Dayside auroral hydrogen emission as an aeronomic signature of magnetospheric boundary layer processes, Geophys. Res. Lett., 25, 2111-2114, doi:10.1029/98GL01535, 1998.

Eather, R. H.: Red Shift of Auroral Hydrogen Profiles, J. Geophys. Res., 71, 5027-5032, 1966.

Eather, R. H.: Secondary Processes in Proton Auroras, J. Geophys. Res., 72, 1481, 1967a.

Eather, R. H.: Auroral proton precipitation and hydrogen emissions, Rev. Geophys., 5, 207-285, 1967 b.

Eather, R. H. and Burrows, K. M.: Excitation and ionization by auroral protons, Aust. J. Phys., 19, 309-322, 1966. 
Eather, R. H. and Jacka, F.: Auroral hydrogen emission, Aust. J. Phys., 19, 241-274, 1966.

Edgar, B. C., Miles, W. T., and Green, A. E. S.: Energy deposition of protons in molecular nitrogen and applications to proton auroral phenomena, J. Geophys. Res., 78, 6595-6606, 1973.

Edgar, B. C., Porter, H. S., and Green, A. E. S.: Proton energy deposition in molecular and atomic oxygen and applications to the polar cap, Planet. Space Sci., 23, 787-804, doi:10.1016/0032-0633(75)90015-X, 1975.

Fang, X., Liemohn, M. W., Kozyra, J. U., and Solomon, S. C.: Quantification of the spreading effect of auroral proton precipitation, J. Geophys. Res. - Space Physics, 109, A04309, doi:10.1029/2003JA010119, 2004.

Fleischmann, H. H., Young, R. A., and McGowan, J. W.: Differential Charge-Transfer Cross Section for Collisions of $\mathrm{H}^{+}$on $\mathrm{O}_{2}$, Phys. Rev., 153, 19-22, doi:10.1103/PhysRev.153.19, 1967.

Galand, M.: Transport des protons dans l'ionosphère aurorale, Thèse de l'Université Joseph Fourier, Grenoble, 1996.

Galand, M.: Introduction to special section: Proton precipitation into the atmosphere, J. Geophys. Res., 106, 1-6, doi:10.1029/2000JA002015, 2001.

Galand, M. and Chakrabarti, S.: Proton aurora observed from the ground, J. Atmos. Terr. Phys., 68, 1488-1501, doi:10.1016/j.jastp.2005.04.013, 2006.

Galand, M., Lilensten, J., Kofman, W., and Sidje, R. B.: Proton transport model in the ionosphere 1. Multistream approach of the transport equations, J. Geophys. Res., 102, 22 261-22 272, doi:10.1029/97JA01903, 1997.

Galand, M., Lilensten, J., Kofman, W., and Lummerzheim, D.: Proton transport model in the ionosphere. 2. Influence of magnetic mirroring and collisions on the angular redistribution in a proton beam, Ann. Geophys., 16, 1308-1321, 1998, http://www.ann-geophys.net/16/1308/1998/.

Galand, M., Baumgardner, J., Pallamraju, D., Chakrabarti, S., Løvhaug, U. P., Lummerzheim, D., Lanchester, B. S., and Rees, M. H.: Spectral imaging of proton aurora and twilight at Troms $\varnothing$, Norway, J. Geophys. Res. - Space Physics, 109, A07305, doi:10.1029/2003JA010033, 2004.

Gao, R. S., Johnson, L. K., Hakes, C. L., Smith, K. A., and Stebbings, R. F.: Collisions of kilo-electron-volt $\mathrm{H}^{+}$and $\mathrm{He}^{+}$ with molecules at small angles - Absolute differential cross sections for charge transfer, Phys. Rev. A, 41, 5929-5933, doi:10.1103/PhysRevA.41.5929, 1990.

Gartlein, C. W.: Auroral spectra showing broad hydrogen lines, Trans. Am. Geophys. Union, 31, 18-20, 1950.

Gartlein, C. W.: Protons and the Aurora, Nature, 167, 277, doi:10.1038/167277a0, 1951a.

Gartlein, C. W.: Protons and the Aurora, Phys. Rev., 81, 463-464, doi:10.1103/PhysRev.81.463.2, 1951b.

Hardy, D. A., Gussenhoven, M. S., and Holeman, E.: A statistical model of auroral electron precipitation, J. Geophys. Res., 90, 4229-4248, 1985.

Hubert, B., Gérard, J. C., Fuselier, S. A., Mende, S. B., and Burch, J. L.: Proton precipitation during transpolar auroral events: Observations with the IMAGE-FUV imagers, J. Geophys. Res. Space Physics, 109, A06204, doi:10.1029/2003JA010136, 2004.

Iglesias, G. and Vondrak, R. R.: Atmospheric spreading of protons in auroral arcs, J. Geophys. Res., 79, 280-282, 1974.

Jasperse, J. R.: Transport theoretic solutions for the beam-spreading effect in the proton-hydrogen aurora, Geophys. Res. Lett., 24, 1415-1418, doi:10.1029/97GL01271, 1997.

Jasperse, J. R. and Basu, B.: Transport theoretic solutions for auroral proton and $\mathrm{H}$ atom fluxes and related quantities, J. Geophys. Res., 87, 811-822, 1982.

Johnstone, A. D.: The spreading of a proton beam by the atmosphere, Planet. Space Sci., 20, 292-297, 1972.

Kozelov, B. V.: Influence of the dipolar magnetic field on transport of proton-H atom fluxes in the atmosphere, Ann. Geophys., 11, 697-704, 1993,

http://www.ann-geophys.net/11/697/1993/.

Kozelov, B. V. and Ivanov, V. E.: Monte Carlo calculation of proton-hydrogen atom transport in N2, Planet. Space Sci., 40, 1503-1511, doi:10.1016/0032-0633(92)90047-R, 1992.

Kozelov, B. V. and Ivanov, V. E.: Effective energy loss per electronion pair in proton aurora, Ann. Geophys., 12, 1071-1075, 1994, http://www.ann-geophys.net/12/1071/1994/.

Lanchester, B. S., Galand, M., Robertson, S. C., Rees, M. H., Lummerzheim, D., Furniss, I., Peticolas, L. M., Frey, H. U., Baumgardner, J., and Mendillo, M.: High resolution measurements and modeling of auroral hydrogen emission line profiles, Ann. Geophys., 21, 1629-1643, 2003,

http://www.ann-geophys.net/21/1629/2003/.

Lathuillère, C. and Kofman, W.: A short review on the F1-region ion composition in the auroral and polar ionosphere, Adv. Space Res., 37, 913-918, doi:10.1016/j.asr.2005.12.014, 2006.

Lerner, J. M. and Thevenon, A.: The optics of spectroscopy, a tutorial 2.0, Jobin Yvon Optical Systems, Instruments SA, 1988.

Lilensten, J. and Blelly, P. L.: The TEC and F2 parameters as tracers of the ionosphere and thermosphere, J. Atmos. Terr. Phys., 64, 775-793, 2002.

Lilensten, J. and Galand, M.: Proton-electron precipitation effects on the electron production and density above EISCAT (Troms $\varnothing$ ) and ESR, Ann. Geophys., 16, 1299-1307, 1998, http://www.ann-geophys.net/16/1299/1998/.

Lilensten, J., Blelly, P. L., Kofman, W., and Alcaydé, D.: Auroral ionospheric conductivities: a comparison between experiment and modeling, and theoretical f 10.7 -dependent model for EISCAT and ESR, Ann. Geophys., 14, 1297-1304, 1996, http://www.ann-geophys.net/14/1297/1996/.

Lorentzen, D. A.: Latitudinal and longitudinal dispersion of energetic auroral protons, Ann. Geophys., 18, 81-89, 2000, http://www.ann-geophys.net/18/81/2000/.

Lorentzen, D. A., Sigernes, F., and Deehr, C. S.: Modeling and observations of dayside auroral hydrogen emission Doppler profiles, J. Geophys. Res., 103, 17479-17488, doi:10.1029/98JA00885, 1998.

Lorentzen, D. A., Kintner, P. M., Moen, J., Sigernes, F., Oksavik, K., Ogawa, Y., and Holmes, J. M.: Pulsating dayside aurora in relation to ion upflow events during a northward IMF dominated by a strongly negative IMF By, J. Geophys. Res., accepted, doi:10.1029/2006JA011757, 2007.

Lummerzheim, D. and Galand, M.: The profile of the hydrogen $\mathrm{H}_{\beta}$ emission line in proton aurora, J. Geophys. Res., 106, 23-32, doi:10.1029/2000JA002014, 2001.

Lummerzheim, D. and Lilensten, J.: Electron transport and energy degradation in the ionosphere: Evaluation of the numerical solution, comparison with laboratory experiments and auroral observations, Ann. Geophys., 12, 1039-1051, 1994, 
http://www.ann-geophys.net/12/1039/1994/.

Meinel, A. B.: The spectrum of the airglow and the aurora, Reports of Progress in Physics, 14, 121-146, 1951.

Newman, J. H., Chen, Y. S., Smith, K. A., and Stebbings, R. F.: Differential cross sections for scattering of 0.5-, 1.5-, and 5.0$\mathrm{keV}$ hydrogen atoms by $\mathrm{He}, \mathrm{H} 2, \mathrm{~N} 2$, and $\mathrm{O} 2$, J. Geophys. Res., 91, 8947-8954, 1986.

Ogawa, Y., Fujii, R., Buchert, S. C., Nozawa, S., Watanabe, S., and van Eyken, A. P.: Simultaneous EISCAT Svalbard and VHF radar observations of ion upflows at different aspect angles, Geophys. Res. Lett., 27, 81-84, doi:10.1029/1999GL010665, 2000.

Ogawa, Y., Buchert, S. C., Fujii, R., Nozawa, S., and Forme, F.: Naturally enhanced ion-acoustic lines at high altitudes, Ann. Geophys., 24, 3351-3364, 2006, http://www.ann-geophys.net/24/3351/2006/.

Omholt, A.: Characteristics of auroras caused by angular dispersed protons, J. Atmos. Terr. Phys., 9, 18-27, 1956.

Rees, M. H.: On the interaction of auroral protons with the earth's atmosphere, Planet. Space Sci., 30, 463-472, doi:10.1016/0032-0633(82)90056-3, 1982.

Robertson, S. C., Lanchester, B. S., Galand, M., Lummerzheim, D., Stockton-Chalk, A. B., Aylward, A. D., Furniss, I., and Baumgardner, J.: First ground-based optical analysis of $\mathrm{H}_{\beta}$ Doppler profiles close to local noon in the cusp, Ann. Geophys., 24, $2543-$ 2552, 2006,

http://www.ann-geophys.net/24/2543/2006/.

Sigernes, F.: Estimation of initial auroral proton energy fluxes from Doppler profiles, J. Atmos. Terr. Phys., 58, 1871-1883, 1996.

Sigernes, F., Lorentzen, D. A., Deehr, C. S., and Henriksen, K.: Calculation of auroral Balmer volume emission height profiles in the upper atmosphere, J. Atmos. Terr. Phys., 56, 503-508, 1994.

Sigernes, F., Shumilov, N., Deehr, C. S., Nielsen, K. P., Svenøe, T., and Havnes, O.: Hydroxyl rotational temperature record from the auroral station in Adventdalen, Svalbard $\left(78^{\circ} \mathrm{N}, 15^{\circ} \mathrm{E}\right)$, J. Geophys. Res. - Space Physics, 108, 3-1, doi:10.1029/2001JA009023, 2003.

Simon, C.: Contribution to the study of energy inputs from solar origin in the ionosphere: doubly-charged ions and proton kinetic transport - Application to the Earth and Titan, $\mathrm{PhD}$ thesis, Thèse de l'Université Joseph Fourier, Grenoble, http://tel. archives-ouvertes.fr/tel-00109802, 2006.
Solomon, S. C.: Auroral particle transport using Monte Carlo and hybrid methods, J. Geophys. Res., 106, 107-116, doi:10.1029/2000JA002011, 2001.

Søraas, F. and Aarsnes, K.: Observations of ENA in and near a proton arc, Geophys. Res. Lett., 23, 2959-2962, doi:10.1029/96GL02821, 1996.

Søraas, F., Lindalen, H. R., Måseide, K., Egeland, A., Sten, T. A., and Evans, D. S.: Proton precipitation and the $\mathrm{H}_{\beta}$ emission in a postbreakup auroral glow, J. Geophys. Res., 79, 1851-1859, 1974.

Søraas, F., Maseide, K., Torheim, P., and Aarsnes, K.: Dopplershifted auroral H-beta emission: A comparison between observations and calculations, Ann. Geophys., 12, 1052-1064, 1994, http://www.ann-geophys.net/12/1052/1994/.

Stamnes, K.: Analytic approach to auroral electron transport and energy degradation, Planet. Space Sci., 28, 427-441, doi:10.1016/0032-0633(80)90046-X, 1980.

Strickland, D. J., Daniell, Jr., R. E., Jasperse, J. R., and Basu, B.: Transport-theoretic model for the electron-proton-hydrogen atom aurora. 2: Model results, J. Geophys. Res., 98, $21533-$ $21548,1993$.

van Zyl, B. and Neumann, H.: H-alpha and H-beta emission cross sections for low-energy $\mathrm{H}$ and $\mathrm{H}^{+}$collisions with $\mathrm{N}_{2}$ and $\mathrm{O}_{2}, \mathrm{~J}$. Geophys. Res., 85, 6006-6010, 1980.

Vegard, L.: Hydrogen showers in the auroral region, Nature, 144, 1089-1090, 1939.

Vegard, L.: Emission spectra of night sky and aurora, Report of the Gassiot Committee, The Physical Society London, 1948.

Vegard, L. and Tønsberg, E.: Results from auroral spectrograms obtained at Troms $\varnothing$ observatory during the winters 1941-1942 and 1942-1943, Geophys. Publik., 16, 1-12, 1944.

Winningham, J. D. and Heikkila, W. J.: Polar cap auroral electron fluxes observed with Isis 1, J. Geophys. Res., 79, 949-957, 1974.

Yousif, F. B., Geddes, J., and Gilbody, H. B.: Balmer alpha emission in collisions of $\mathrm{H}, \mathrm{H}(+), \mathrm{H}_{2}(+)$ and $\mathrm{H}_{3}(+)$ with $\mathrm{N}_{2}, \mathrm{O}_{2}$ and $\mathrm{H}_{2} \mathrm{O}$, J. Phys. B: At. Mol. Phys., 19, 217-231, 1986. 